\title{
LAS DESTREZAS PERCEPTUALES Y LOS RETOS EN EL APRENDIZAJE DE LA LECTURA Y LA ESCRITURA. UNA GUÍA PARA LA EXPLORACIÓN Y COMPRENSIÓN DE DIFICULTADES ESPECÍFICAS.
}

\section{Laura Bravo Cóppola ${ }^{1}$}

Resumen: Se ofrece a continuación un acercamiento conceptual y didáctico a las destrezas perceptuales que se vinculan directamente con el aprendizaje de la lectura y la escritura con el propósito de evidenciar, la relevancia de conocer el nivel de desempeño de los y las niñas en el uso de las destrezas perceptuales; nivel de desempeño que incide directamente en el desarrollo de competencias en el ámbito académico. Para ello se presenta una Guía de Exploración Diagnóstica que consiste en la presentación de una definición conceptual y operacional de cada una de las sub-áreas de la Percepción Visual y Auditiva (las áreas más vinculadas con el aprendizaje de la lectura y la escritura), así como la descripción de una serie de indicadores conductuales que pueden orientar al docente en la implementación posterior de los apoyos que cada estudiante requiera para lograr exitosamente aprender a leer y escribir.

Palabras claves: PERCEPCIÓN/ ÁREAS PERCEPTUALES/ DIFICULTADES/

\begin{abstract}
A conceptual and didactic approach is offered next to the perceptual skills that directly tie with the learning of the reading and the writing in order to demonstrate, the relevance to know the level performance of and the children in the use of the perceptual skills; performance level that affects the development of competitions in the academic scope directly. For it Guide of Exploration Diagnosis appears that consists of the presentation of a conceptual and operational definition of each one of the sub-area of the Visual and Auditory Perception (the most tie areas with the learning of the reading and the writing), as well as the description of a series of conductual indicators that can orient to the educational one in the later implementation of the supports that each student requires to manage successful to learn to read and to write.
\end{abstract}

Key words: PERCEPTION/ PERCEPTION AREAS/ DIFFICULTIES/

\section{INTRODUCCIÓN}

La percepción es la base para todo aprendizaje. Por medio de la percepción el individuo da significado a la información que recibe mediante los sentidos tanto internos como externos. Para ello en el cerebro se da un proceso de interpretación y clasificación de los datos recibidos que permiten posteriormente a la persona, elaborar conceptos simples y complejos a nivel cognitivo. Las diferentes teorías del desarrollo humano coinciden en que la base del desarrollo cognitivo lo son los procesos cognitivos. La lectura y escritura como parte de estos procesos cognitivos requieren de una madurez perceptiva especialmente en las áreas visual y auditiva.

\footnotetext{
${ }^{1}$ Master en Psicopedagogía en la Universidad de La Salle, Master en Estudios Interdisciplinarios sobre Discapacidad con énfasis en Discapacidad Múltiple y Sordoceguera; Licenciatura en Educación Especial con énfasis en Discapacidad Múltiple y Severa, Bachiller en Educación, todos los títulos de la Universidad de Costa Rica. Profesora de la Escuela de Orientación y Educación Especial; Directora del Programa Regional de Recursos en Sordera y Coordinadora de la Sección de Educación Especial.
}

Correo electrónico: Ibravocr@yahoo.es

Artículo recibido: 21 de enero, 2004

Aprobado: 21 de junio, 2004 
Por otra parte, es muy frecuente que se presenten necesidades educativas especiales en el ámbito de la lectura y la escritura. La lectura es una actividad cognitiva sumamente compleja en la que intervienen diversos procesos léxicos, sintácticos y semánticos, y por esto es frecuente que muchos escolares presenten dificultades para adquirirla o dominarla (Sánchez y Torres, 1998).

El presente trabajo plantea parte de los hallazgos de un estudio realizado en el año 2000 con escolares de 5 a 8 años de edad, ubicados en el sistema regular en los niveles de preescolar, primero y segundo año respectivamente en la provincia de Cartago con quienes se piloteó una Guía de Observación de Destrezas Perceptuales. Particularmente una síntesis de los contenidos que conciernen al marco referencial teórico de dicha Guía, que permiten posteriormente el uso práctico de la Guía en la práctica docente cotidiana. Dichos contenidos no pretenden dar la orientación teórica básica que posibilite la comprensión apropiada de los indicadores de posibles necesidades educativas especiales en el ámbito del desarrollo perceptual que se contemplan.

\section{Concepto de percepción}

\subsection{Percepción}

La percepción es el proceso de organización e interpretación de los datos sensoriales (sensaciones) para desarrollar la conciencia del entorno y de uno mismo. La percepción implica interpretación y la sensación no.

Para introducirnos en el ámbito de las destrezas perceptuales es necesario comprender que el desarrollo perceptual es la base de todo aprendizaje, a la vez, es una parte del desarrollo cognoscitivo que, se inicia en el niño por medio de las experiencias psicomotrices. Por ello vamos a entender la secuencia del desarrollo de las destrezas perceptuales en el marco del desarrollo integral del niño, basándonos en las etapas del desarrollo cognoscitivo que plantea Piaget en su teoría del desarrollo intelectual, ya que esta perspectiva nos permite integrar las destrezas motoras hasta llegar a una etapa donde las destrezas propiamente perceptuales se constituyen en el eje principal del aprendizaje. Esto permite dar paso al desarrollo de procesos conceptuales como la lectura y la escritura, lo cual ocurre alrededor de los siete años de edad en el niño.

Es muy importante aclarar que el patrón de desarrollo que se plantea en la presente propuesta, responde a un proceso madurativo que nos ubica más en la perspectiva de proceso, que en pautas de desarrollo basadas en edades cronológicas específicas. 
En este contexto, las habilidades serán entendidas como la capacidad innata que tiene un individuo para ejecutar una tarea, y las destrezas la calidad de la ejecución de una tarea que desarrolla una persona por medio del entrenamiento.

\subsubsection{Naturaleza de la percepción}

Cohen (1991, p. 9) define percepción como la "interpretación significativa de las sensaciones como representantes de los objetos externos, la percepción es el conocimiento de lo que está afuera".

Cabe mencionar que los sentidos se clasifican en internos y externos. Los externos son la vista, el oído, el tacto, el olfato, el gusto, es decir, que responden a estímulos provocados por un objeto externo (Wilson, Robeck, y William, 1978, p. 398).

Los internos se refieren a los sentidos que se "activan" sin relación con objetos externos, entre ellos se ubican el sentido vestibular y el cinestésico que son importantes para el desarrollo de percepciones como el esquema corporal: esto es lo que se conoce como propiocepción (sensaciones que emergen del propio cuerpo de la persona). "Los científicos han catalogado once sentidos distintos" (Davidoff, 1994, p. 152), sin embargo para efecto del tema tratado sólo nos interesan los anteriormente citados.

La percepción es un proceso complejo que es a la vez cognoscitivo y fisiológico y no siempre inicia en el individuo sino que puede iniciar con la experiencia, es decir con un estímulo.

En el proceso de la percepción, entonces, intervienen un estímulo, un receptor y una sensación.

Según Cohen (1991) estos elementos se pueden definir como sigue:

a. Estímulo es "una energía física que produce actividad nerviosa en un receptor" (p.6). Se puede decir, por ejemplo que la luz activa al ojo, el sonido al oído y el calor a la piel. El estímulo se distingue del objeto del estímulo. Como menciona este autor en la misma página ya citada, el estímulo es por ejemplo, la energía luminosa que choca con el ojo, mientras que el objeto de estímulo es la fuente luminosa: una lámpara.

b. Receptor es "una estructura anatómica sensible a los estímulos físicos" (p.6). Los receptores se ubican encada sentido, y son una o un grupo de células "que en particular son sensibles a un tipo especifico de energía" (Davidoff, 1994, p.152). Son receptores entonces, el ojo, el oído, la nariz, la lengua, la piel, los músculos y el 
aparato vestibular. Un receptor responde a más de un tipo de energía, sin embargo lo hace al máximo a un estímulo adecuado y parcialmente a estímulos inadecuados. Como cita el mismo Cohen "el ojo responde al máximo, a la estimulación con energía luminosa y solo parcialmente a la estimulación con energía eléctrica" (p.8).

c. Sensación es "el simple correlato experimentado de la estimulación del receptor. Es un acontecimiento interno separado de objetos externos" (p.8). Las sensaciones se caracterizan por su intensidad (fuertes, débiles, brillantes, oscuras) su calidad (rojas, cálidas, dolorosas) y su duración (breves, cortas, intermitentes, largas).

d. Las sensaciones dependen del nervio sensitivo estimulado y existen diferencias individuales en las sensaciones. Un mismo estímulo provoca diferentes sensaciones en diferentes personas.

La percepción es un proceso cognoscitivo, una forma de conocer el mundo.

Es un proceso complejo que depende tanto del mundo que nos rodea como de quien percibe. Por eso es necesario seleccionar y preparar cuidadosamente el material didáctico para trabajar los procesos perceptivos con el niño. Además esto explica el por qué a veces, un mismo material didáctico puede resultar eficaz con un niño y con otro no.

En los procesos perceptivos intervienen entonces, ciertas habilidades constructivas de la persona, la filosofía y la experiencia en sí.

\subsubsection{Aspecto Fisiológico de la Percepción}

Según Davidoff (1994) la operación de la percepción se puede dividir en tres subprocesos desde el punto de vista fisiológico:

a. Detección. Intervienen los receptores, es decir los sentidos, tanto internos como externos.

b. Transducción y transmisión. Procesos donde se convierte energía de una forma a otra (la energía en una señal electroquímica que el sistema nervioso transmite). La misma autora, menciona como forma de ilustración de este proceso lo que sucede con la reproducción de una cinta, de cassette. También podemos ilustrar este proceso con lo que sucede con la música reproducida por discos compactos.

c. Procesamiento de la información. "El cerebro y los receptores procesan información sensorial en organismos de relativa simplicidad" ( p. 152). 


\subsection{Percepción y Atención}

Es importante distinguir la atención de la percepción. La atención como apunta Davidoff (1994) es una "apertura selectiva hacia una pequeña parte de los fenómenos sensoriales incidentes" (p. 148). Un ejemplo ilustrativo lo presenta la misma autora, en la página antes citada, cuando afirma que la atención es "como una cámara de cine se enfoca en un evento primero y luego en otro, los estímulos que se alojan en la periferia o límite de la atención constituyen un fondo".

Existen dos corrientes psicológicas acerca de la naturaleza de la atención.

a. La atención es solo una parte de la percepción. Esto implica que el acto de percibir requiere de selectividad.

b. La atención es una capacidad bien definida, por lo general, se le contempla como un filtro que elimina cierta información. Esta capacidad iría en función de los requerimientos de las tareas a realizar. Los científicos cognoscitivos consideran que puede haber percepción sin atención y un ejemplo de ello serían los actos automáticos como manejar y escribir a máquina (Papalia y Wendkos, 1992).

Es conveniente distinguir la atención de la percepción, porque para efectos del siguiente estudio, los ejercicios propuestos para valorar los procesos perceptivos que está elaborando el(la) niño(a), la atención será un pre-requisito indispensable y la inatención un factor que afectará en forma determinante las ejecuciones particulares de los estudiantes.

\subsection{Implicaciones de la percepción en el aprendizaje}

Procesos psicológicos superiores, como el aprendizaje, la memoria, la creación y discriminación son función de las capacidades perceptuales del organismo (Cohen, 1991, p. 8).

El maestro o psicopedagogo puede intervenir en el proceso de la percepción específicamente en la entrada de la información y en la salida de ésta, es decir, con la mediación en la respuesta que tenga el niño. En otras palabras, el quehacer del psicopedagogo se relaciona con los receptores (los sentidos) y los efectores (músculos, articulaciones que permiten desplazamiento y movimiento). Con los sentidos, ha de buscar los mejores objetos de estímulo que permitan iniciar un proceso perceptivo particular, lo que se relaciona directamente con los procesos de motivación y enseñanza, y selección de recursos didácticos específicos, que muchas veces serán los factores determinantes de las destrezas perceptuales que desarrolla un estudiante en particular. Por otra parte, con respecto a la salida de la información, es necesario, que se contemple la individualidad y se 
valoren todos los posibles medios de respuesta que respeten el estilo de aprendizaje y las características personales y así hacer realidad la atención a la diversidad.

Las percepciones, entonces son dinámicas y en ellas intervienen la creatividad, la imaginación y la experiencia.

Para poder hacer uso de la guía que se propone en el presente artículo es necesario revisar algunos conceptos relacionados con las áreas y sub-áreas perceptuales que sirven de base para la organización de las destrezas perceptuales vinculadas con la lectura y la escritura.

\subsubsection{Esquema corporal}

Generalmente cuando se habla de Esquema Corporal en términos de un contenido curricular a desarrollar se piensa en enseñar a los estudiantes a nombrar y ubicar las diferentes partes del cuerpo, tanto en sí mismo como en los demás y por último a nivel gráfico. Sin embargo es pertinente aclarar que para desarrollar el esquema corporal como lo definimos anteriormente, los estudiantes han de integrar tres nociones que se definen a continuación.

a. Imagen: Concepto subjetivo, depende del concepto que el individuo tenga de sí mismo, experiencias con los demás, sus metas en la vida y su estado afectivo; es inconsciente. A través de distintas sensaciones que se funden en una estructura mental unitaria, nos representamos a nosotros mismos, a nuestro cuerpo. Es decir, que la imagen es la representación mental que tenemos de nosotros mismos y por lo tanto implica un concepto del cuerpo y también un sentimiento relativo a esto: cómo sentimos que somos.

b. Concepto: Es algo intelectual, es conocer todas y cada una de las partes del cuerpo por su nombre y la función de las mismas. Es consciente y se construye con base en experiencias de aprendizaje. Se dice que primero se forma la imagen y luego el concepto. Se trabaja entres niveles: concreto en sí mismo, en otros y en láminas.

c. Esquema: Es inconsciente, se deriva de sensaciones táctiles, cinestésicas, regula los diferentes músculos y partes del cuerpo en un momento dado y cambia según la posición del cuerpo. Nos da coordinación de los músculos y regula la postura. Por eso se evalúa mediante imitación de posiciones. Como la definición lo dice es una integración de todas las sensaciones y percepciones relativas al cuerpo.

Siempre en esta área es importante aclarar la concepción en torno a las destrezas vinculadas con el área de la motricidad cuyo desarrollo está íntimamente ligado con los procesos perceptuales. Para ello, seguidamente se enuncian una serie de nociones que se 
consideran básicas por incorporarse directamente en los procesos de enseñanza y aprendizaje de la lectura y la escritura.

d. Motricidad fina: Movimientos de los músculos finos del cuerpo (especialmente manos y dedos).

e. Motricidad gruesa: Movimientos de los músculos gruesos del cuerpo ( tronco, brazos y piernas).

f. Coordinación visomotriz ( fina y gruesa): Coordinar movimientos con algo que se ve.

g. Habilidades de movimiento:

Entre las habilidades del movimiento podemos mencionar dos básicas:

g.1. Equilibrio: - dinámico: habilidad de mantener el cuerpo estable y controlado mientras está en movimiento.

- estático: habilidad de mantener el cuerpo estable y controlado en una posición estática. Ej. : estar sentado, escribir.

g.2. Agilidad: habilidad de cambiar direcciones rápidamente y efectivamente mientras se está en movimiento a máxima velocidad.

g.3. Flexibilidad: Facilidad de realizar movimientos de flexión y extensión.

g.4. Coordinación: Uso simultáneo de partes del cuerpo.

Tanto las habilidades del movimiento antes mencionadas como las cualidades del movimiento están estrechamente vinculadas con los procesos de escritura.

h. Cualidades del movimiento:

h.1. Fuerza: tensión muscular necesaria para mover cuerpo o partes del mismo manteniendo el equilibrio.

h.2. Tiempo: Velocidad del movimiento.

h.3. Continuidad: Secuencia de los movimientos.

h.4. Espacio: Área que ocupa el cuerpo general o específico. Se refiere a niveles direcciones y distancias.

h.5. Ambiente: Se refiere al lugar donde se dan los movimientos que hacen que las sensaciones sean diferentes: materiales como el zacate, el suelo, etc.

Se señalan conceptos relacionados con la educación del movimiento, por la trascendencia que el movimiento tiene para con el desarrollo del Esquema Corporal, la lateralidad y la direccionalidad, las relaciones espaciales y espacio-temporales. Además porque en las ejecuciones motoras, como lo es el acto de escribir, el propio movimiento en sí mismo, también es fuente información sensorial a través de dos sentidos específicos: 
- Sentido cinestésico: Informa con respecto a la posición relativa de las partes del cuerpo durante el movimiento. Ejemplo: al hacer movimientos con los ojos cerrados este sentido hace que nos percatemos de la maniobra. Este sentido hace posible advertir de manera constante lo que hacen las partes del cuerpo y equilibrar la tensión muscular en todo el cuerpo para poder realizar movimientos eficientes. Ej. No dejar caer algo. Los receptores se encuentran en las articulaciones, músculos y tendones.

- Sentido vestibular: Sentido de la orientación y el equilibrio. Da información acerca del movimiento y orientación de la cabeza y el cuerpo con respecto a la tierra conforme se desplazan las personas por sí mismas y cuando son impulsados por carros, aviones, barcos u otros vehículos. Ej. El columpio. Los receptores están en el oído interno en la parte ósea del cráneo. Este sentido ayuda a la visión ( lo que se mueve es la cabeza, los ojos se mueven a la vez y no aparte a la hora de girar por ejemplo durante un seguimiento visual). Este sentido permite que la persona mantenga postura durante el movimiento.

Junto con el sentido cinestésico y el sentido visual permiten la orientación del cuerpo en el espacio. Es necesario tener esto presente cuando se pretenden desarrollar las nociones especiales mediante un programa específico.

\subsubsection{Lateralidad y direccionalidad}

No hay un acuerdo entre psicólogos con relación a esta definición de la lateralidad pues por ejemplo existen algunos que opinan que esta se puede enseñar. Por esto incluso a nivel pedagógico nos encontraremos con libros de ejercicios que pretenden enseñarla y la definen además como sinónimo de direccionalidad.

Según Kephart para mantener el equilibrio el niño tiene que aprender cuando debe activar los músculos de un lado del cuerpo y cuando los del otro. De aquí la importancia de una lateralidad definida.

De los 4 a los 6 años de edad, la preferencia unilateral predomina. Se supone que al llegar a la escuela a los 7 años ya el niño tiene su lateralidad definida. Existen dos criterios para determinar la predominancia de una mano, la preferencia y la eficiencia de su utilización. 


\section{Organización de las relaciones en el tiempo. Estructuración espacio- temporal.}

La orientación y estructuración temporal se refiere al hecho de que así como el niño debe llegar a situarse en el espacio, igualmente debe hacerlo con respecto al tiempo. La conciencia del tiempo y la duración de éste tiene que ser estable. El niño debe adquirir la capacidad de reproducir la secuencia cronológica de los hechos, uno tras de otro, teniendo conciencia de su duración. Esta noción está vinculada a la del espacio. La adquisición de una se realiza en función de la otra. Tiempo y espacio son dimensiones de la misma realidad. Todos los días se nos exigen conversiones de tiempo y espacio y viceversa. La misma forma en que medimos el tiempo es un ejemplo: el reloj y la lectura.

En nuestro contexto escolar particular donde atender a la diversidad es un constante reto, el hecho de que las y los docentes entiendan la naturaleza de los procesos perceptivos que intervienen en la lectura, les permitirá discernir con más precisión las necesidades de apoyo personal que demandan los estudiantes.

Los docentes regulares requieren, muchas veces, de orientaciones específicas por parte de un docente de apoyo, es decir de educación especial, para así en conjunto atender de forma integral las necesidades educativas especiales en el ámbito de la lectura y la escritura.

Por ello a continuación se expone una guía de exploración diagnóstica que facilita la valoración funcional y comprensiva de algunos retos específicos de aprendizaje en el contexto de la lectura y la escritura.

\section{Lectura y Percepción}

Aunque no existe un acuerdo teórico que nos permita formular una definición integrada de lo que es la lectura, es evidente que existen dos tipos de conceptos que se distinguen claramente. Los que ponen énfasis a los procesos de decodificación y los que lo hacen en la noción de significado o comprensión. Cada una de estas perspectivas se sustentan en una posición epistemológica determinada de cada profesional que conduce a planteamientos particulares de las características de los procesos de lecto-escritura y las intervenciones pedagógicas pertinentes.

Independientemente del énfasis que se le ponga a las habilidades de decodificación o a las de dar significado, el niño para aprender a leer necesita como aportan Garton y Pratt citados por Sánchez y Torres (1998) "desarrollar habilidades para decodificarla palabra escrita con el fin de encontrar su equivalente en la palabra hablada" (p. 54). 
Como afirman Rivas y Fernández (1994) citando a García Vidal,

... son requisitos para el correcto aprendizaje de la escritura y la ortografía en el ámbito perceptivo, las destrezas de discriminación auditiva, integración auditiva, memoria auditiva, discriminación y figura-fondo visual, constancia de la forma, memoria visual, estructuración temporal y en el ámbito motor, una lateralización adecuada (lateralidad definida) y motricidad dinámica manual. (p. 102).

\section{Relación entre los retos de aprendizaje específicos en la lectura y la escritura y los procesos perceptuales}

Para poder enfrentar exitosamente el aprendizaje de la lectura y la escritura, se requieren de ciertas destrezas que involucran los procesos perceptivos, tanto en percepción visual como en percepción auditiva, básicamente discriminación auditiva; también se requieren de destrezas motrices en el uso de manos y dedos para lograr ejecutar labores de escritura, esto implica a la vez una regulación tónico postural general que le permita al estudiante manejar la estructuración espacio-temporal para codificar y decodificar las letras. Tanto la percepción visual como la auditiva, entonces, son "factores que inciden en el rendimiento escolar y las actividades de aprestamiento le ayudan al niño(a) a desarrollarlas al máximo" (González, 1981, p. 43).

Muchas de las dificultades lectoras que presentan estudiantes con necesidades educativas especiales, se derivan de dificultades en los procesos de orientación espacial como resultado de una falla en establecer la dominancia lateral, lo cual hace que el lector perciba visualmente en forma distorsionada y confunda, entonces, perceptualmente algunos fonemas-grafemas; estas dificultades también se asocian con la memoria visual y la orientación espacial (Condemarín, 1989).

Según Condemarín (1989):

Se ha podido comprobar que en las habilidades fonológicas es donde se producen las mayores dificultades, estas habilidades requieren de información perceptiva de los sonidos y de los signos, discriminación y segmentación acústica en el contexto fonemático de la palabra y la categorización fonética y secuenciación, categorización de la palabra como conjunto sonoro, debido a la tendencia a percibir sonidos similares en el contexto de la agrupación fonemática ( p. 55). 
Por otra parte, como afirman Frostig, Horne y Miller (1992) "es frecuente que aparezcan disfunciones de la percepción en los primeros años escolares y su eficiencia es muy importante para el éxito del aprendizaje inicial' (p. 7). Además muchos errores ortográficos se deben a dificultades en la percepción y discriminación auditiva.

Si consideramos, entonces el papel de las destrezas perceptuales como pre-requisitos indispensables para poder elaborar las nociones conceptuales que involucran la lectura y la escritura, el(la) maestro(a) debería conocer a fondo el proceso de desarrollo perceptual de los niños y las niñas, especialmente de aquellos que presentan necesidades educativas especiales, para así determinar los apoyos que se han de implementar en cada caso.

\section{Procedimiento Metodológico}

El procedimiento empleado consistió en la aplicación de la Guía de Observación de Destrezas Perceptuales a una muestra a conveniencia conformada por treinta niños con edades entre los 5 y 8 años ubicados en dos centros educativos (uno público y otro privado) en los niveles de Kinder, Preparatoria, primero y segundo grado. La Guía, instrumentos diseñado como parte de la experiencia profesional en apoyo y valoración pedagógica con estudiantes con necesidades educativas especiales y utilizado en el ejercicio de cotejo de tareas que involucran las destrezas perceptuales que desarrollan los niños a esas edades.

El instrumento se sometió a juicio de expertos con tres profesionales en Psicopedagogía, Educación Especial y Preescolar previo a su administración. Se aplicó en las instituciones educativas donde ellos asistían, dentro y fuera del aula según los requerimientos de espacio de cada una de las actividades a realizar. La aplicación del instrumento se realizó en forma compartida con las docentes a los estudiantes, a quienes se les entregó el material didáctico y el instructivo. Posterior a la aplicación de la Guía se realizó el análisis estadístico de los datos que permitió concluir que el Instructivo de la Guía, puede ser utilizado por docentes de primaria, preescolar y educación especial.

\section{Guía de exploración de necesidades en las áreas perceptuales}

A continuación se plantea una síntesis de las áreas perceptuales, donde se incluye una definición operacional de las habilidades que corresponden a cada área y se anotan también dificultades comunes que pueden presentar los(as) estudiantes en cada una de las mencionadas áreas. Estas dificultades son únicamente ejemplos y no se pueden tomar en términos absolutos para clasificar o etiquetar de ningún modo a los(as) estudiantes, pues los 
indicadores que se citan pueden tener además relación con otras áreas del desarrollo. Cabe mencionar que una dificultad en un área perceptual específica puede estar directamente relacionada con otra, pues el desarrollo es un proceso integral. Al respecto es esencial recalcar que, es necesario integrar las sensaciones visuales, auditivas, tactiles, propioceptivas y de otra clase para que el estudiante se desenvuelva exitosamente en el contexto de los procesos de enseñanza-aprendizaje formal.

El presente planteamiento está redactado en función de la implicación directa que tienen las mencionadas áreas perceptuales en el aprendizaje de la lectura, la escritura y puede ser útil además como guía exploratoria de necesidades que permitan posteriormente un abordaje pedagógico individualizado.

\section{Area: Percepción Visual}

La percepción visual es la capacidad de discriminar y reconocer los estímulos visuales y de interpretarlos asociándolos con experiencias anteriores.

\begin{tabular}{|c|c|c|}
\hline Sub-área & Definición & Indicadores o características \\
\hline $\begin{array}{c}\text { Recepción } \\
\text { Visual }\end{array}$ & $\begin{array}{l}\text { Habilidad para } \\
\text { comprender y } \\
\text { derivar significado } \\
\text { de lo que se ve. }\end{array}$ & $\begin{array}{l}\text { a. Dificultad para repetir secuencias de una } \\
\text { historia con láminas. } \\
\text { b. Dificultad para interpretar láminas. } \\
\text { No le gustan los juegos visuales. }\end{array}$ \\
\hline $\begin{array}{c}\text { Asociación } \\
\text { Visual }\end{array}$ & $\begin{array}{l}\text { Habilidad para dar } \\
\text { significado y } \\
\text { clasificar lo que ve. }\end{array}$ & $\begin{array}{l}\text { a. Dificultad para nombrar objetos } \\
\text { presentados visualmente (colores, figuras, } \\
\text { etc.). } \\
\text { b. Dificultad para aprender a leer el reloj. } \\
\text { c. Dificultad para recordar el nombre de sus } \\
\text { compañeros asociándolos con sus caras. }\end{array}$ \\
\hline $\begin{array}{c}\text { Discriminación } \\
\text { Visual }\end{array}$ & $\begin{array}{lr}\text { Habilidad para ver } \\
\text { semejanzas } & \mathrm{y} \\
\text { diferencias. } & \end{array}$ & $\begin{array}{l}\text { a. Dificultad para desarrollar un } \\
\text { vocabulario visual. } \\
\text { b. Sustituir e invertir (b-d, es-se, otras) } \\
\text { Estos errores también pueden ser } \\
\text { consecuencias de dificultades de las } \\
\text { relaciones espacio-temporales. } \\
\text { c. Dificultad para escoger y aparear. }\end{array}$ \\
\hline
\end{tabular}




\begin{tabular}{|c|c|c|}
\hline $\begin{array}{c}\text { Figura Fondo } \\
\text { Visual }\end{array}$ & $\begin{array}{l}\text { Habilidad para } \\
\text { percibir los objetos } \\
\text { en un fondo. }\end{array}$ & $\begin{array}{l}\text { a. Apariencia de desatento y desorganizado. } \\
\text { b. Dificultad para localizar detalles. } \\
\text { c. Confusión para ubicarse en las páginas de } \\
\text { un cuaderno o libro. } \\
\text { d. Dificultad para identificar figuras, números } \\
\text { en una página. } \\
\text { e. Presencia de errores de omisión por } \\
\text { ejemplo deja sin resolver partes de los } \\
\text { ejercicios contenidos, en una página, omitir } \\
\text { sílabas o palabras o repetición de } \\
\text { renglones al copiar. } \\
\text { f. Dificultad para observar mayúsculas y } \\
\text { minúsculas. } \\
\text { g. Dificultad para localizar palabras } \\
\text { conocidas de un texto u oración. } \\
\text { h. Cometer errores de sustitución de sílabas } \\
\text { y palabras. }\end{array}$ \\
\hline Cierre Visual & $\begin{array}{l}\text { Habilidad } \text { para } \\
\text { reconocer el todo } \\
\text { cuando sólo se } \\
\text { presenta una parte. }\end{array}$ & $\begin{array}{l}\text { a. No poder completar rompecabezas de } \\
\text { acuerdo a lo esperado para su edad. } \\
\text { b. Omitir parte de las palabras al escribir } \\
\text { espontáneamente o bien al copiar. } \\
\text { c. Dificultad para adivinar lo que falta en una } \\
\text { lámina, palabra u oración cuando sólo se } \\
\text { le presenta una parte. }\end{array}$ \\
\hline $\begin{array}{c}\text { Memoria } \\
\text { Visual }\end{array}$ & $\begin{array}{l}\text { Habilidad para } \\
\text { revisualizar y retener } \\
\text { imágenes que ha } \\
\text { visto previamente. } \\
\text { Hay básicamente } \\
\text { dos tipos que nos } \\
\text { interesan en el } \\
\text { contexto de la } \\
\text { lectura y la escritura: }\end{array}$ & $\begin{array}{l}\text { a. Dificultad para recordar secuencias de } \\
\text { números o el alfabeto por escrito. } \\
\text { b. Dificultad para recordar lo que se vio en } \\
\text { una película, un paseo o un viaje. } \\
\text { c. No reconocer su propia ropa o trabajo } \\
\text { (pierde todo). } \\
\text { d. En la etapa inicial de la lectura falla al } \\
\text { reconocer sílabas y palabras a golpe de } \\
\text { vista. }\end{array}$ \\
\hline
\end{tabular}




\begin{tabular}{|c|c|c|}
\hline & $\begin{array}{lr}\text { memoria } & \text { visual } \\
\text { inmediata } & y \\
\text { secuencial. } & \end{array}$ & $\begin{array}{l}\text { e. Fallas en el dictado en vocabulario de uso } \\
\text { frecuente y/o elementos comunes. } \\
\text { Comete errores en la copia por copiar letra } \\
\text { a letra o palabra a palabra. } \\
\text { f. Dificultad para decir la hora en reloj de } \\
\text { agujas. }\end{array}$ \\
\hline $\begin{array}{c}\text { Constancia } \\
\text { Perceptual } \\
\text { Visual }\end{array}$ & 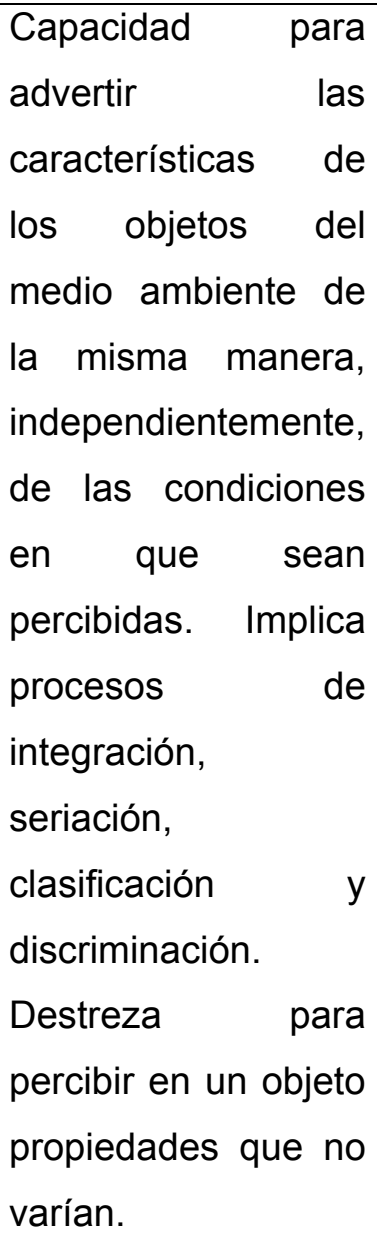 & $\begin{array}{l}\text { a. Dificultad para aprender algunos } \\
\text { colores. } \\
\text { b. Conocer una sílaba aislada pero no en } \\
\text { la palabra. } \\
\text { c. Dificultad al reconocer una palabra en } \\
\text { un texto. } \\
\text { d. Dificultad al reconocer las mismas } \\
\text { palabras o letras escritas con diferente } \\
\text { color o tamaño. }\end{array}$ \\
\hline$C$ & $\begin{array}{lr}\begin{array}{l}\text { Capacidad } \\
\text { agrupar }\end{array} & \begin{array}{r}\text { para } \\
\text { haciendo }\end{array} \\
\text { sus coincidir } \\
\text { cualitativos (forma, } \\
\text { colores, texturas, } \\
\text { etc.) y cuantitativos }\end{array}$ & $\begin{array}{l}\text { a. No poder agrupar los mismos objetos } \\
\text { según diferentes variables (color, forma, } \\
\text { tamaño). } \\
\text { b. Se le dificulta agrupar palabras según } \\
\text { diferentes variables (letra con la que } \\
\text { empieza, número de sílabas, etc. }\end{array}$ \\
\hline
\end{tabular}




\begin{tabular}{|c|c|c|}
\hline & 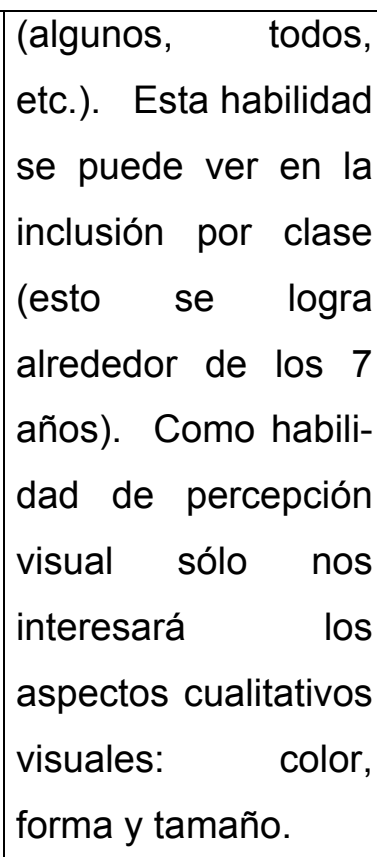 & $\begin{array}{l}\text { Nota: } \\
\text { Esta destreza además de ser un proceso } \\
\text { perceptual es un proceso cognitivo (lógico- } \\
\text { matemático), por esto se incluye también entre las } \\
\text { destrezas pre-numéricas. }\end{array}$ \\
\hline Seriación & $\begin{array}{lr}\text { Capacidad r de } & \text { de } \\
\text { ordenación } & \text { detos en } \\
\text { objeten } \\
\text { decreciente, puede } \\
\text { ser por grosor, } \\
\text { tamaño, } \\
\text { grados de dureza, } \\
\text { etc. Como habilidad } \\
\text { perceptual visual } \\
\text { sólo nos interesan } \\
\text { los aspectos de } \\
\text { tamaño, grosor, } \\
\text { color (perceptibles } \\
\text { visualmente). }\end{array}$ & $\begin{array}{l}\text { a. Completar series ordenadas en forma } \\
\text { decreciente o creciente con tamaños, colores } \\
\text { (tonalidades), etc. } \\
\qquad \underline{\text { Nota: }} \\
\text { Esta es un área que además de ser un proceso } \\
\text { perceptual implica un proceso conceptual, por } \\
\text { esto se incluye también en algunas guías } \\
\text { didácticas o curriculares como parte de las } \\
\text { destrezas pre-numéricas. }\end{array}$ \\
\hline Integración & $\begin{array}{l}\text { Proceso por medio } \\
\text { del cual se pueden } \\
\text { percibir las formas } \\
\text { como una totalidad, } \\
\text { lo cual permite } \\
\text { reproducirlas en otro }\end{array}$ & $\begin{array}{l}\text { a. Omitir parte de las palabras al escribir o } \\
\text { leer. } \\
\text { b. Se le dificulta adivinar lo que falta en una } \\
\text { lámina, palabra y oración. } \\
\text { c. Se le dificulta armar rompecabezas que ha } \\
\text { visto terminados previamente. }\end{array}$ \\
\hline
\end{tabular}




\begin{tabular}{|l|l|l|}
\hline $\begin{array}{l}\text { plano. Integrar las } \\
\text { partes en un todo. }\end{array}$ & \multicolumn{1}{c|}{$\begin{array}{c}\text { Nota: } \\
\text { Esta habilidad implica un proceso perceptual- } \\
\text { motor y se aplica en la lectura y escritura y en el } \\
\text { aprendizaje de conceptos numéricos por ser éstos } \\
\end{array}$} \\
& $\begin{array}{l}\text { un todo constituido por partes unificadas que } \\
\text { guardan relación entre sí. }\end{array}$ \\
\hline
\end{tabular}

IMPORTANTE: Por la íntima relación que tiene la percepción visual en el desarrollo de las nociones espaciales se pueden considerar a las relaciones espaciales como una sub-área del área visual por lo que se mencionarán también como aquellas necesarias para el desarrollo de la lectura y escritura.

\begin{tabular}{|c|c|c|c|}
\hline $\begin{array}{l}\text { Relaciones } \\
\text { Espaciales }\end{array}$ & $\begin{array}{llr}\text { Habilidad } & \text { para } \\
\text { percibir } & \text { posiciones } \\
\text { mutuas } & \text { de } & \text { dos } \\
\text { objetos. } & & \\
\end{array}$ & $\begin{array}{l}\text { a. } \\
\text { b. } \\
\text { c. } \\
\text { d. } \\
\text { e. } \\
\text { f. }\end{array}$ & $\begin{array}{l}\text { Dificultad para el ordenamiento de las } \\
\text { letras en palabras. } \\
\text { Dificultad para el ordenamiento de } \\
\text { palabras en oraciones. } \\
\text { Dificultad para memorizar el proceso de } \\
\text { la división y la multiplicación en } \\
\text { aritmética. } \\
\text { Dificultad para copiar modelos y ubicarse } \\
\text { en la página al copiar de la pizarra. } \\
\text { Dificultad para leer mapas. } \\
\text { Frecuentes errores de escritura como la } \\
\text { rotación y la inversión. Es importante } \\
\text { distinguir entre un error ortográfico por } \\
\text { inadecuado manejo de las relaciones } \\
\text { espaciales y uno en percepción visual } \\
\text { como lo sería la distorsión. } \\
\text { Dificultad para indicar lo que hay a la } \\
\text { derecha o izquierda de un objeto que se } \\
\text { encuentre al frente de sí mismo. } \\
\text { Equivocaciones frecuentes al usar } \\
\text { conceptos de arriba, abajo, etc. }\end{array}$ \\
\hline
\end{tabular}




\begin{tabular}{|c|c|c|}
\hline & & $\begin{array}{l}\text { i. Dificultad para aprender colores y el } \\
\text { nombre de figuras geométricas. } \\
\text { j. Confundir letras al leer al -la les -sé. } \\
\text { Inversiones en el orden de dígitos: } 15 \\
\text { por } 51 \text {. Al escribir puede no respetar los } \\
\text { renglones. }\end{array}$ \\
\hline $\begin{array}{c}\text { Orientación } \\
\text { Espacial }\end{array}$ & $\begin{array}{l}\text { Son las relaciones } \\
\text { que se establecen } \\
\text { para estructurar el } \\
\text { espacio externo } \\
\text { concretamente en } \\
\text { cuanto a determinar } \\
\text { la posición de un } \\
\text { objeto o imagen o } \\
\text { símbolo gráfico } \\
\text { respecto a las } \\
\text { nociones } \\
\text { espaciales. }\end{array}$ & $\begin{array}{l}\text { a. Comete errores de inversión de letras, } \\
\text { sílabas y números. } \\
\text { b. Se pierde al copiar de la pizarra, siempre } \\
\text { y cuando no se trate por falta de } \\
\text { desarrollo de la memoria visual } \\
\text { inmediata. } \\
\text { c. Dificultad al hacer uso adecuado de } \\
\text { márgenes y renglones al copiar o escribir } \\
\text { espontáneamente. }\end{array}$ \\
\hline $\begin{array}{c}\text { Coordinación } \\
\text { Visomotora }\end{array}$ & $\begin{array}{l}\text { Habilidad para } \\
\text { realizar con la } \\
\text { mano lo que ve el } \\
\text { ojo. }\end{array}$ & $\begin{array}{l}\text { a. Borrones y tachones frecuentes. } \\
\text { b. Letra temblorosa o demasiado repintada. } \\
\text { c. Movimientos corporales aleatorios al } \\
\text { escribir. } \\
\text { d. "Mala letra" (caligrafía). } \\
\text { e. Lentitud notoria al escribir. } \\
\text { f. En etapas más avanzadas tiene dificultad } \\
\text { en la transición de la letra script a la } \\
\text { cursiva. } \\
\text { g. Se le dificulta mantenerse dentro del } \\
\text { renglón al escribir. } \\
\text { h. Al final de los ejercicios escritos se nota } \\
\text { que la calidad del trabajo empeora. }\end{array}$ \\
\hline
\end{tabular}




\section{Área: Percepción auditiva.}

La percepción auditiva es la facultad de reconocer y discriminar los estímulos auditivos (sonidos) y de interpretarlos.

\begin{tabular}{|c|c|c|}
\hline $\begin{array}{c}\text { Recepción } \\
\text { Auditiva }\end{array}$ & $\begin{array}{l}\text { Habilidad para } \\
\text { comprender y } \\
\text { derivar significado } \\
\text { de lo que escucha. }\end{array}$ & $\begin{array}{l}\text { a. No sigue instrucciones orales simples. } \\
\text { b. No responde apropiadamente en las } \\
\text { discusiones de clase. } \\
\text { c. No entiende ni se ríe de los chistes. } \\
\text { d. No le gustan los juegos orientados } \\
\text { verbalmente. }\end{array}$ \\
\hline $\begin{array}{c}\text { Asociación } \\
\text { Auditiva }\end{array}$ & 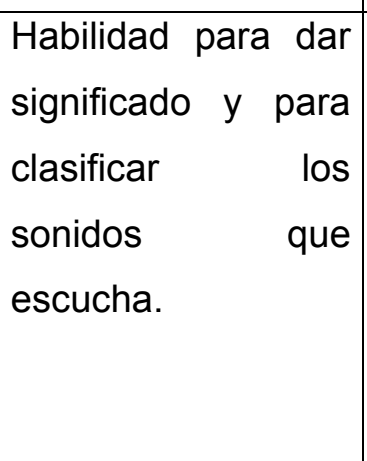 & $\begin{array}{l}\text { a. Dificultad para nombrar objetos, } \\
\text { actividades, etc. } \\
\text { b. No asocia ni reconoce sonidos del } \\
\text { ambiente que le rodea. } \\
\text { c. Pobre uso del lenguaje al responder } \\
\text { oralmente. } \\
\text { d. Problemas con las palabras antónimas. }\end{array}$ \\
\hline $\begin{array}{c}\text { Discriminación } \\
\text { Auditiva }\end{array}$ & \begin{tabular}{|lr} 
Habilidad & para \\
escuchar & \\
semejanzas & $y$ \\
diferencias. & \\
\end{tabular} & $\begin{array}{l}\text { a. Dificultad para asociar sonido-letra. } \\
\text { b. Dificultad para distinguir palabras que } \\
\text { riman. } \\
\text { c. Confusión al escuchar palabras cuya } \\
\text { pronunciación es similar. }\end{array}$ \\
\hline $\begin{array}{c}\text { Figura- fondo } \\
\text { Auditiva }\end{array}$ & $\begin{array}{l}\text { Habilidad para no } \\
\text { prestar atención a } \\
\text { los } r \text { sonidos } \\
\text { relevantes r y } \\
\text { atender los sonidos } \\
\text { pertinentes a lo que } \\
\text { debe realizar. }\end{array}$ & $\begin{array}{l}\text { a. Fácilmente se distrae con los ruidos. } \\
\text { b. Se queja de mucho ruido. } \\
\text { c. No puede escuchar cuando se habla al } \\
\text { mismo tiempo. } \\
\text { d. No logra discernir cual es el estímulo } \\
\text { auditivo relevante. }\end{array}$ \\
\hline
\end{tabular}




\begin{tabular}{|c|c|c|}
\hline $\begin{array}{c}\text { Cierre y Fusión } \\
\text { Auditiva }\end{array}$ & $\begin{array}{l}\text { Habilidad para } \\
\text { completar patrones } \\
\text { auditivos. }\end{array}$ & $\begin{array}{l}\text { a. No puede reconocer una palabra } \\
\text { cuando se le presenta parcialmente. } \\
\text { b. No puede comprender una conversación } \\
\text { rápida. } \\
\text { c. Dificultad para comprender las palabras } \\
\text { en las canciones. } \\
\text { d. No puede unir sonidos para formar } \\
\text { palabras. }\end{array}$ \\
\hline $\begin{array}{l}\text { Memoria } \\
\text { Auditiva }\end{array}$ & $\begin{array}{l}\text { Habilidad para } \\
\text { recordar } \\
\text { espontáneamente } \\
\text { lo que escucha. }\end{array}$ & $\begin{array}{l}\text { a. No recuerda como suenan las cosas. } \\
\text { b. Dificultad para repetir (días de la } \\
\text { semana, meses del año, etc.) } \\
\text { c. No recuerda la secuencia de los sonidos } \\
\text { en las palabras. } \\
\text { d. No recuerda versos, canciones, rimas, } \\
\text { chistes. } \\
\text { e. Es común que no recuerde las tablas de } \\
\text { multiplicar. } \\
\text { f. Falla en el dictado fonético. } \\
\text { g. Solicita que se le repitan las palabras al } \\
\text { dictado. } \\
\text { h. Dificultad para percibir acentos en las } \\
\text { palabras. } \\
\text { i. Dificultad para fijar la asociación del } \\
\text { fonema con su grafema } \\
\text { correspondiente. } \\
\text { j. Dificultad para seguir instrucciones } \\
\text { orales ( omite pasos de los que } \\
\text { componen la instrucción). }\end{array}$ \\
\hline $\begin{array}{c}\text { Conducta } \\
\text { Auditivo-Motora }\end{array}$ & $\begin{array}{lr}\text { Capacidad r de } \\
\text { ejecutar lo que nos } \\
\text { llega } & \text { auditivamente } \\
\text { a través de } & \text { de } \\
\text { movimientos. }\end{array}$ & $\begin{array}{l}\text { a. No puede seguir órdenes verbales } \\
\text { consecutivas. } \\
\text { b. Se pierde cuando se le dan } \\
\text { instrucciones verbales. }\end{array}$ \\
\hline
\end{tabular}




\begin{tabular}{|l|l|}
\hline $\mid$\begin{tabular}{|l|}
$|c|$ \\
\hline
\end{tabular} & $\begin{array}{l}\text { Nota: } \\
\text { No se deben olvidar las áreas que también } \\
\text { tienen directa relación con el aprendizaje de la } \\
\text { lectura y escritura: esquema corporal, } \\
\text { lateralidad, direccionalidad y estructuración } \\
\text { espacio-temporal. }\end{array}$ \\
\hline
\end{tabular}

\section{Area: Esquema Corporal}

Es la "organización de las sensaciones relativas al propio cuerpo, en relación con los datos del mundo exterior" (MEP, 1980, p. 38). Se requiere de un punto de referencia en torno al cual organizar las impresiones que recibimos.

\begin{tabular}{|c|c|c|}
\hline $\begin{array}{c}\text { Esquema } \\
\text { Corporal }\end{array}$ & 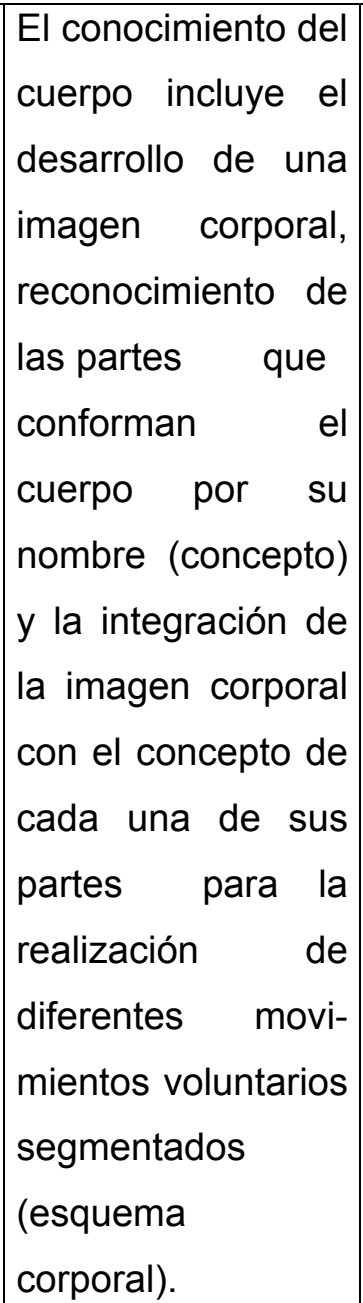 & $\begin{array}{l}\text { a. Confunde el nombre de las partes } \\
\text { del cuerpo o no puede localizarlas } \\
\text { adecuadamente. } \\
\text { b. Expresa una pobre imagen de sí } \\
\text { mismo verbalmente o mediante } \\
\text { dibujos. } \\
\text { c. Dificultad para imitar posiciones } \\
\text { como levantar un pie y la mano } \\
\text { opuesta a la vez. }\end{array}$ \\
\hline
\end{tabular}




\begin{tabular}{|c|c|c|}
\hline Direccionalidad & 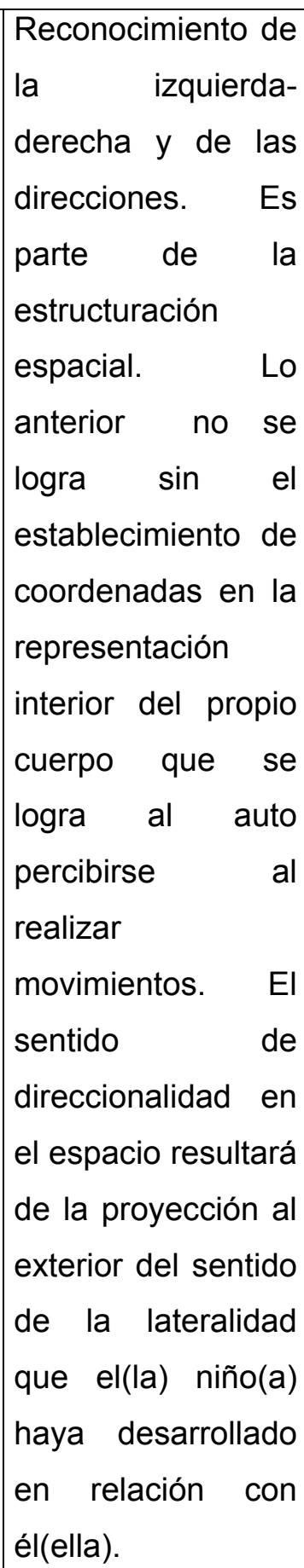 & $\begin{array}{l}\text { a. Dificultad para ubicar las partes del } \\
\text { cuerpo en el lado derecho o } \\
\text { izquierdo.(Esto se da a los } 5 \text { o } 6 \\
\text { años.) } \\
\text { b. Dificultad para seguir órdenes } \\
\text { cruzadas. (entre los } 6 \text { y } 7 \text { años). } \\
\text { c. Dificultad para seguir órdenes } \\
\text { cruzadas con ojos abiertos y } \\
\text { cerrados. }\end{array}$ \\
\hline Lateralidad & $\begin{array}{l}\text { Dominación natural } \\
\text { de un lado del } \\
\text { cuerpo más que el } \\
\text { otro. Es el dominio } \\
\text { funcional del }\end{array}$ & $\begin{array}{l}\text { a. No define una mano en actividades tales } \\
\text { como cortar papel, escribir, pintar. Usa } \\
\text { las dos indistintamente sin ser } \\
\text { ambidiestro(a). }\end{array}$ \\
\hline
\end{tabular}




\begin{tabular}{|c|c|c|}
\hline & $\begin{array}{l}\text { cerebro de derecha } \\
\text { o izquierda de: } \\
\text { mano, ojo, pie y } \\
\text { oído. }\end{array}$ & \\
\hline $\begin{array}{c}\text { Estructuración } \\
\text { espacio-temporal }\end{array}$ & $\begin{array}{l}\text { Ubicación en el } \\
\text { tiempo } \\
\text { representada en el } \\
\text { espacio gráfico. }\end{array}$ & $\begin{array}{l}\text { a. En la realización de sus actividades } \\
\text { habituales, como por ejemplo, el } \\
\text { juego, tienen problemas de } \\
\text { orientación. } \\
\text { b. Dificultad para leer y copiar letras } \\
\text { simétricas y parecidas (podre por } \\
\text { pobre), y para situarlas en su orden } \\
\text { o posición correctos (pardo por } \\
\text { prado). } \\
\text { c. Dificultades para establecer } \\
\text { coordenadas geográficas y/o para } \\
\text { captar la sucesión temporal de } \\
\text { acontecimientos históricos. }\end{array}$ \\
\hline
\end{tabular}

\section{Consideraciones finales}

Para facilitar cualquier aprendizaje, más que conocer de didácticas específicas los docentes han de tener claros los procesos cognitivos, en este caso concreto de la lectura y la escritura, que se han de producir en cada estudiante para que se dé el aprendizaje. Sólo comprendiendo el funcionamiento en cada ámbito del desarrollo es posible que el docente conduzca procesos de enseñanza-aprendizaje donde las necesidades educativas no se conviertan en especiales gracias a una oportuna intervención didáctica que potencie la enseñanza individualizada. La enseñanza de la lectura y la escritura como aprendizajes conceptuales no puede desvincularse del desarrollo del lenguaje y en general del desarrollo integral del niño, donde las destrezas perceptuales juegan un papel determinante. 


\section{REFERENCIAS}

Ahumada, Montenegro y Ahumada. (1993). Jugando Aprendemos. México: Trillas.

Arguedas, S. (s.f.). Áreas Perceptuales. Manuscrito no publicado. San José: Universidad de Costa Rica.

Bravo, L. (1996). Áreas Perceptuales. Manuscrito no publicado. San José: Universidad de Costa Rica.

Carles de Velarde, M. (s.f.). Pre-escritura. España: Decasa, Susaeta.

Chacón Ramírez, F. M. (s.f.). Huellitas y Algo Más. España: Decasa, Susaeta.

Chacón Ramírez, F. M. (s.f.). Tijeritas y Algo Más. España: Decasa, Susaeta.

Chacón, N. (1974). Laboratorio de percepción y discriminación auditiva. Editorial Taller de Publicaciones U.N.A.

Chacón, N. (1987). Triquitran. Percepción y discriminación auditiva. San José: Lehmann Editores.

Cohen, J. (1991a). Sensación y Percepción auditiva y de los sentidos menores. México: Trillas.

Cohen, J. (1991b). Sensación y Percepción visuales. México: Trillas.

Condemarín, M. (s.f.). Hurganito. Chile: Editorial Universitaria.

Condemarín, M., Chadwick, M. (1998). La escritura creativa y formal. Santiago de Chile: Editorial Andrés Bello.

Costa Rica, Ministerio de Educación Pública, Asesoría Nacional de Problemas de Aprendizaje. (1980). Prueba Integral de Exploración de Dificultades en el Aprendizaje. San José: Ministerio de Educación Publica.

Costa Rica, Ministerio de Educación Pública, Asesoría Nacional y Asesoría Regionales de problemas de aprendizaje. (1980). Prueba integral exploratoria de dificultades de aprendizaje (P.I.E.D.A.), San José: El Ministerio.

Davidoff, L. (1994). Introducción a la Psicología. México: Mc Graw Hill.

Domínguez, M., Rodríguez, S. (1979). Programas de desarrollo escolar para alumnos lentos. Madrid: INTERDUC/SCHROEDEL.

Fontanals, O. (1988). PIO PIO. Uruguay: Editorial Kapelusz.

Frostig, M., Horne, D., Miller, A. (1992). Figuras y Formas. México: Editorial Médica Panamericana.

González, L. (1981). El desarrollo Psicológico del niño. Bogotá: Norma. 
Hernández P., R., Rodríguez A., S. (1995). Manual operativo para la evaluación y estimulación del crecimiento y desarrollo del niño. San José: EUNED.

Instituto Costarricense de Enseñanza Radiofónica. (1990). Mi libro de Prácticas. Serie de prácticas graduadas para ayudar al desarrollo de las capacidades del niño. San José, Costa Rica: Ed. COOPEICER.

Major, S., Walsh, M. A. (1983). Actividades para niños con problemas de aprendizaje. Barcelona: Ediciones CEAC.

Miranda C., A. (1994). Introducción a las dificultades en el aprendizaje. Valencia: Promolibro.

Mohar Fernández, V. (1995). Despacito. México: Noriega Editores.

Papalia, D., Wendkos, S. (1992). Psicología del desarrollo de la infancia a la adolescencia. México: Mc Graw Hill.

Rivas T., R., Fernández F., P. (1994). Dislexia, Disortografía y Disgrafía. Madrid: Pirámide.

Rodríguez Rescia, M. (1995). Juegos Creativos y la Iniciación en la Lectoescritura. San José: Editec Editores.

Silva de Mejía, M. E. (1989). Guía practica para el Desarrollo de la Psicomotricidad. Colección didáctica contemporánea. Guatemala: Editorial Piedra Santa.

Wilson, J., Robeck, M., William, M. (1978). Fundamentos Psicológicos del Aprendizaje y la Enseñanza. (s.I.): ANAYA.

Zamora Z., D. (1998). La Evaluación dela niña y del niño en Educación Preescolar. San José: EUNED. 